\title{
Hydraulic Hold Rail Brake Design of Inclined Roadway Vehicles
}

\section{Hengjin XIANG ${ }^{1, a}$, Jian SUN ${ }^{1, b}$, Kang $X U^{1, c}$}

${ }^{1}$ Mechanical and Electronic Department, Xuzhou Institute of Technology, Xuzhou, 221111, China

aemail: sunbin275@163.com, bemail: sunjian751@163.com, cemail: 15895233200@163.com

Keywords: Inclined roadway vehicles; Over-speed protection; hydraulic braking system

\begin{abstract}
To improve the inclined lane car braking reliability, in this paper, the theoretical analysis of the braking force and the brake parameters of the inclined roadway are carried out, developed a new type of hydraulic track brake device. The device use two levels of the hydraulic cylinder symmetrically installed on both sides of the rail, the force of the track is uniform, and the braking force is large, avoiding the effects of manufacturing and installation errors on the rail brake and improving the inclined lane of vehicle braking stability and reliability.
\end{abstract}

\section{Introduction}

Slope railway vehicles usually use the steel wire rope traction, in order to adapt to the large gradient transport, but its security problem has been bothering people. Safe and effective braking is the key to the inclined lane rail vehicle safety. Catching trap rail type, cable, plug claw type, hold wheel is the most common form of car braking, but doesn't have a high level of safety reliability. In this paper, the new type inclined lane car braking way, using the hydraulic system to drive the two synchronous clamping cylinder work, hold rail car braking friction plate to achieve people on the device.

\section{Brake Resistance Calculation}

Brake resistance is an important parameter affecting the shaft car brake buffer performance. The brake resistance will cause excessive braking deceleration, thus threatening the personal safety of the passengers; the brake resistance is too small will cause the car to reliable braking, and that the occurrence of car accidents.

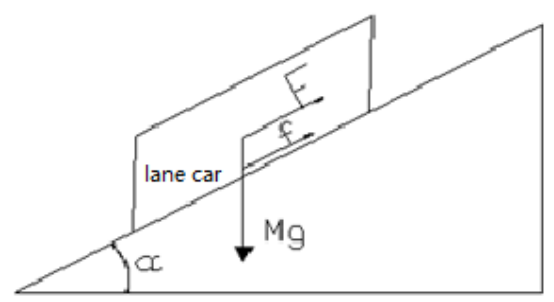

Fig.1. Vehicles force diagram

The force analysis of inclined roadway vehicles during braking is shown in figure 1, by the force balance can be obtained:

$$
\begin{gathered}
F+f-M g \sin \alpha=M a \\
f=M g \varpi \sin \alpha
\end{gathered}
$$

In the type, $\mathrm{f}$-One car running resistance, $\mathrm{F}$ - The braking force, $\alpha$-The Angle of mine, a-Brake deceleration, g-The acceleration of gravity.

In the design of braking deceleration is inclined lane car a very key technical indicators, by formula (1), (2), the average braking deceleration can be slope during the vehicles braking:

$$
a=\frac{M}{M}-(1-\varpi) g \sin \alpha
$$

The technical parameters of slope car people hang see the table below: 
Table1. Table Styles

\begin{tabular}{|l|l|l|l|}
\hline Parameters & Value & Parameters & Value \\
\hline Head of vehicle weight & $2200 \mathrm{~kg}$ & The tail of vehicle weight & $1000 \mathrm{~kg}$ \\
\hline The number of load & 15 & Maximum traction & $60 \mathrm{KN}$ \\
\hline Maximum speed & $4 \mathrm{~m} / \mathrm{s}$ & Maximum buffer distance & $1.4 \mathrm{~m}$ \\
\hline Air travel time & $0.2 \mathrm{~s}$ & Damping coefficient & 0.02 \\
\hline
\end{tabular}

In the current effective MT388-2007 standard explicitly defines the braking deceleration refers to the average braking deceleration and brake process its estimation computation formula is as follows:

$$
a=\frac{v^{2}}{2 s}
$$

In the type, $a$-The average braking deceleration, $\mathrm{m} / \mathrm{s}^{2} ; v$-Slope of the braking of vehicle speed, $m / s ; S$-Slope car buffer distance, $m$.

When the car is full with maximum braking force as an example calculation:

$$
F=M a+M g \sin \alpha-M g \varpi \sin \alpha
$$

Because of the different Angle oblique lane, the train runs according to the different set of columns. Weight $70 \mathrm{~kg}$ average, passengers 45 people about $3150 \mathrm{~kg}$, section 4 vehicle weight 5400 $\mathrm{kg}$, the total mass $\mathrm{M}=8550 \mathrm{~kg}$; Acceleration of $5.71 \mathrm{~m} / \mathrm{s}$, take $9.8 \mathrm{~N} \mathrm{~g} / \mathrm{kg}, 0.02$, braking force calculation is as follows:

$$
F=48820 N+82114 \times \sin \alpha \quad\left(31^{\circ} \leq \alpha \leq 40^{\circ}\right)
$$

\section{Brake Parameter Selection}

The principle of braking device of hydraulic system is shown in figure 2.

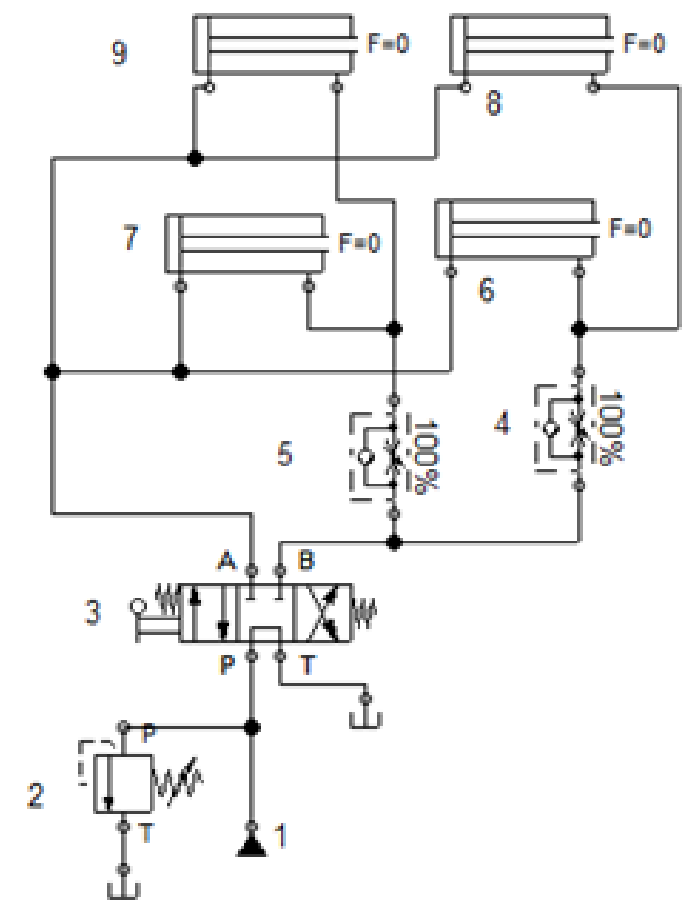

Fig.2. Hydraulic system principle of braking device

1. Hydraulic pump; 2. Overflow valve; 3.Manual directional control valve; 4, 5.

One-way throttle valve; 6 . the brake shoe; 6,7,8,9. The hydraulic cylinder

The system consists of hydraulic pump, relief valve, three four-way reversing valve, one-way throttle valve and hydraulic cylinder. When the vehicle is running, the valve is in the middle position. When emergency braking is required in the process of advance, through to the reversing 
valve left, pressure oil after reversing valve left into the rod less hydraulic cylinder cavity, push the piston rod, the piston cylinder on the brake block contact with guide rail, friction of lining, and parking brake. When the car needs to recover forward, turn right position valve, pressure oil through the valve into the right position the hydraulic cylinder rod chamber, brake blocks and the rail separating at this time, then the car can move on.

The pressure of the hydraulic cylinder is mainly determined by the load, the maximum braking force is expressed as follows.

$$
F=102 k N \quad\left(\alpha=40^{\circ}\right)
$$

In order to ensure that the car move forward without obstruction, the piston rod stroke should not be too small, select $\mathrm{s}=25 \mathrm{~mm}$, so as to select the hydraulic cylinder diameter $\mathrm{D}=200 \mathrm{~mm}^{2}$. According to the technical conditions for mine inclined vehicles, the lost motion time $\mathrm{t}$ is not greater than $0.7 \mathrm{~s}$. So the piston rod speed can be expressed as

$$
v=s / t=0.036 \mathrm{~m} / \mathrm{s}
$$

The size of the piston rod is determined by the following formula:

$$
d_{0}=0.13 D \sqrt{\frac{V}{V_{0}}}
$$

In the type, D-The Inside diameter of hydraulic cylinder, $\mathrm{mm} ; \mathrm{m} / \mathrm{s}^{2} ; \mathrm{V}$-Movement speed of hydraulic cylinder, $\mathrm{m} / \mathrm{s}$; S-Velocity of fluid flow, $\mathrm{m} / \mathrm{s}$, generally not more than $5 \mathrm{~m} / \mathrm{s}$, where to take $4 \mathrm{~m} / \mathrm{s}$.

$$
d_{0}=0.13 D \sqrt{\frac{V}{V 0}}=0.13 \times 200 \sqrt{\frac{0.036}{4}}=25 \mathrm{~mm}
$$

In this paper, the design of the hydraulic cylinder for the clamping cylinder, the use of HKS-16.0 series disc spring, the number of disk spring is calculated as follows

$$
N=S / L=24 / 1.2=20
$$

\section{Working Principle And Structure Design of Brake}

According to stress analysis and the car run time of car resistance calculation, got the car braking when the maximum braking force required size, determine the appearance of the brake hydraulic cylinder size and the size of the system provides the pressure needed. On the basis of the above analysis, this paper designed a set of new rail brake, the brake hydraulic cylinder horizontal, with two hydraulic cylinders placed on the rails, cylinder run at the same time, both sides have the same size of the braking force, braking stable and reliable. The structure schematic diagram as shown:

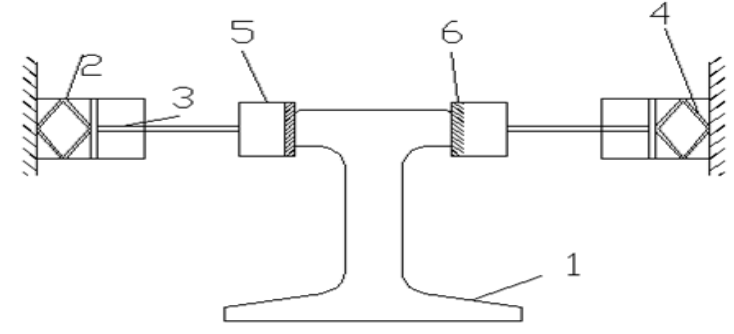

Fig.3. Structure of the rail brake device

1. rail; 2. the hydraulic cylinder; 3. the piston rod;

4. Disc spring; 5 . the brake shoe; 6 . friction plate

Hydraulic cylinder 2 is fixed on a chassis, braking hydraulic oil in the oil chamber to push the piston rod 3 to 3 rail movement, thus brake shoes 5 and the guide rail 1 came into contact with, in order to produce larger brake friction, improve the reliability degree of car braking, on the brake shoe installation friction plate 6 . The friction plate has low cost, good braking performance, easy to install and remove. In the hydraulic cylinder with a disc spring 4, in which the butterfly spring with a reset function, is an essential part of the brake system. When vehicles need to restart, then the butterfly spring accumulation of elastic potential energy, so that the piston cylinder returned to the 
original position, brake shoes, more than 5 friction 6 automatic and rail separation, people and vehicles which is able to start. The brake is a symmetrical device on both sides, so that the car is not due to the brake when the brake is different from the left and right. The level of the hydraulic cylinder is placed, so the rail can only be subjected to the horizontal direction, which can reduce the working pressure of the hydraulic cylinder.

\section{Conclusion}

Based on the theoretical calculation of inclined lane and hydraulic brake related parameters of vehicle braking resistance, this paper design a kind of new rail brake, it is using synchronous hydraulic cylinder to achieve smooth braking. Compared with the traditional human vehicle brake, the new hydraulic rail car brake has the following characteristics: brake travel is short, the braking force is larger and along the rail on both sides of the symmetry, the braking performance is good.

\section{ACKNOWLEDGMENTS}

The research work is supported by National Undergraduate Training Program for Innovation and Entrepreneurship, the Item number: xcx2015008.

\section{References}

[1] Tan Tingshuai, Tian Li. Braking Process Analysis of XRC Type Man Car for Inclined Shaft [J]. Colliery Mechanical \& Electrical Technology, 2013(3): 58-60.

[2] Jiang Shiwen Jiang Hanwu, Li Jinxi. Automatic vehicle hydraulic brake system: China, 200810243979 X [P]. 2008-10-24.

[3] Zhang yuanyue. Hydraulic and hydraulic transmission [M]. Chengdu: southwest jiaotong university press, 2014:149-154.

[4] Zhang Linhui. Explosion-proof rubber-tyred vehicle hydraulic brake system design [J]. Journal of coal mine machinery. 2012.33 (11) : 1-3.

[5] MA Zhi - heng. Lane of Vehicle and Need for Braking Distance Test [J]. Coal Mine Machinery, 2009,30(8): 100-101.

[6] Sun Zhili, cold-hing gather, Wei Yangang mechanical design editor Shenyang: Northeastern University Press, 2000.

[7] MENG Qing- hua, HE Shun- xi. Application of Card Track Wedge Type Braking Inclined Shaft People and Machine Based on Standard Rail [J]. Coal and Chemical Industry, 2015,38(11): 110-111. 